\title{
CFD Simulations to Calculate the Resistance of A 17.500-DWT Tanker
}

\author{
Dian Purnamasari ${ }^{1}$, I Ketut Aria Pria Utama ${ }^{1}$, I Ketut Suastika ${ }^{1}$
}

\begin{abstract}
Numerical simulations have been carried out to determine free surface flow around a tanker 17.500 hull form for which experimental results are available. The SST turbulence model was used in Ansys CFX. The numerical methodology is found to be appropriate for simulating the turbulent flow around a model in order to estimate model total resistance. The computational results are presented in a nondimensional form. By the numerical results, total resistance is calculated for the ship model and the result is satisfactory with regard to the experimental results were compared.
\end{abstract}

Keywords-Tanker Ships, Flow Around The Ship Hull, Numerical Simulation, RANSE.

\section{INTRODUCTION}

Computational Fluid Dynamics (CFD) has been a revolution in the world of engineering and the rapid growth of computer capacities during the past decades has opened new horizons for ship hydrodynamics. CFD is very efficient because it allows exploration of new engineering frontiers in the most economical way. As a result, CFD analysis has become crucial in the design phase of big structures, like ships. Hydrodynamic aspects play an important role in the quality of a ship. Dominant criteria for the hull form design of many ships are the resistance and powering performance. The most dominant application of CFD is the prediction of resistance (64\%), as expected figure 1 . Other applications such as self-propulsion, propulsors, manoeuvring, seakeeping, and ocean engineering are also of great interest with about $40 \%$ of respondents applying CFD to these problems [1].

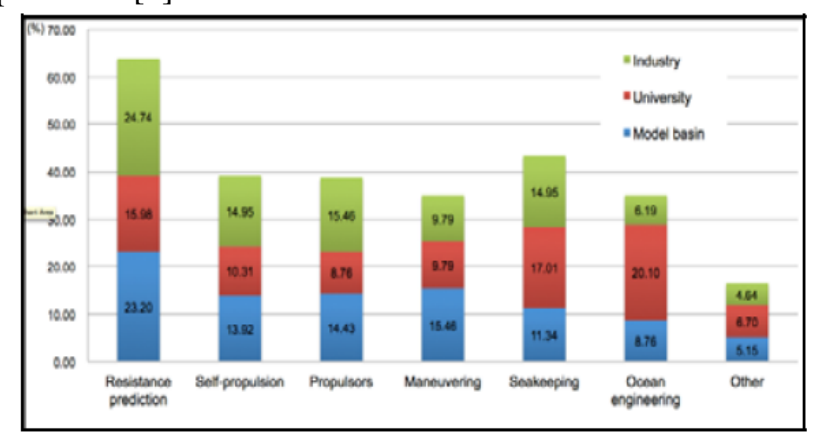

Figure 1. Applications of CFD in Marine Hydrodynamics

\footnotetext{
${ }^{1}$ Dian Purnamasari, I Ketut Aria Pria Utama, and I Ketut Suastika are with Department of of Naval Architecture, Faculty of Marine Technology, Institut Teknologi Sepuluh Nopember (ITS), Kampus ITS Sukolilo, Surabaya 60111, Indonesia. E-mail: dian15@mhs.na.its.ac.id; kutama@na.its.ac.id; k_suastika@na.its.ac.
}

The development of Computational Fluid Dynamics technique has made it possible to numerically model the flow around ship hull. Making computational predictions requires the computations at towing conditions corresponding to the resistance model tests. ITTC 2011 Specialist Committee on Computational Fluid dynamics report provides a detailed review of numerical methods commonly used for ship hydrodynamics [2]. Over the last few decades, RANS based numerical approaches are widely used in ship design. RANS based study was investigated scale effect on ship form factor with Reynolds number for different hull geometries by double body analyses [3]. Design of different skeg geometries and an optimum skeg for a ship via RANS approach are analyzed numerically without free surface. Studied the ship resistance and flow field of KVLCC2 (KRISO Very Large Crude Carrier) both experimentally and numerically with two turbulence models SST (Shear-Stress Transport) $k \omega$ model and EASM (Explicit Algebraic Stress) $k \omega$ Model showed that both turbulence models gave good prediction of resistance, sinkage, trim and wave elevation around the hull, the computed total resistance and resistance on the fore and aft segments of the ship agreed well with the experimental results. [4].

In this work, we present computational results for a surface ship, using free surface calculations. The paper presents a detailed methodology of widely used RANSE based CFD approach. The calculations for the Tanker 17.500 hull form were performed with the flow solver CFX which is based on a finite volume method. In the calm water test, total drag coefficient, values were predicted together with mesh dependency analysis. The results compared with experimental data.

\section{EXPERIMENT AND NUMERICAL}

Total resistance of the tanker 17.500 model made of wood was measured in the towing tank of Indonesian Hydrodynamic Laboratory [5]. A total of 7 experiments for $\mathrm{Fr}$ in the range of 0.133-0.202 was conducted in calm water. The tanker model and measurement equipment can be seen in Figure 2. The results of these towing tank experiments will contribute to the development of Computational Fluid Dynamics (CFD) research in ship hydrodynamics. 


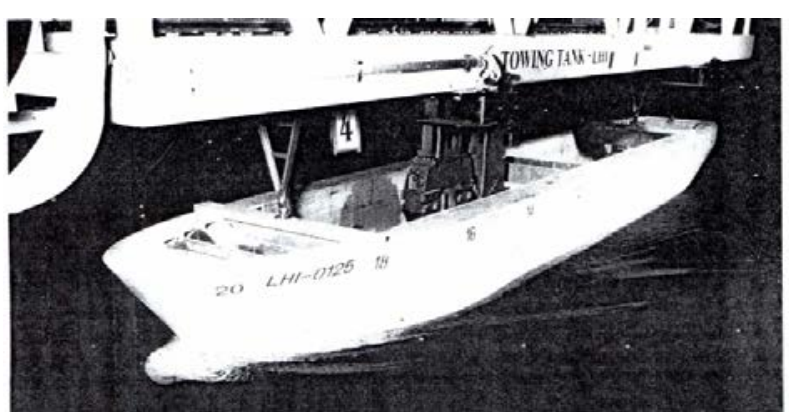

Figure 2. Resistance test of Tanker 17.500 hull

\section{A. Geometry}

The hull form under consideration is the Tanker 17.500 is shown in figure 3 . The particulars of this hull form are presented table 1.

TABLE 1.

GEOMETRICAL PROPERTIES TANKER 17.500.

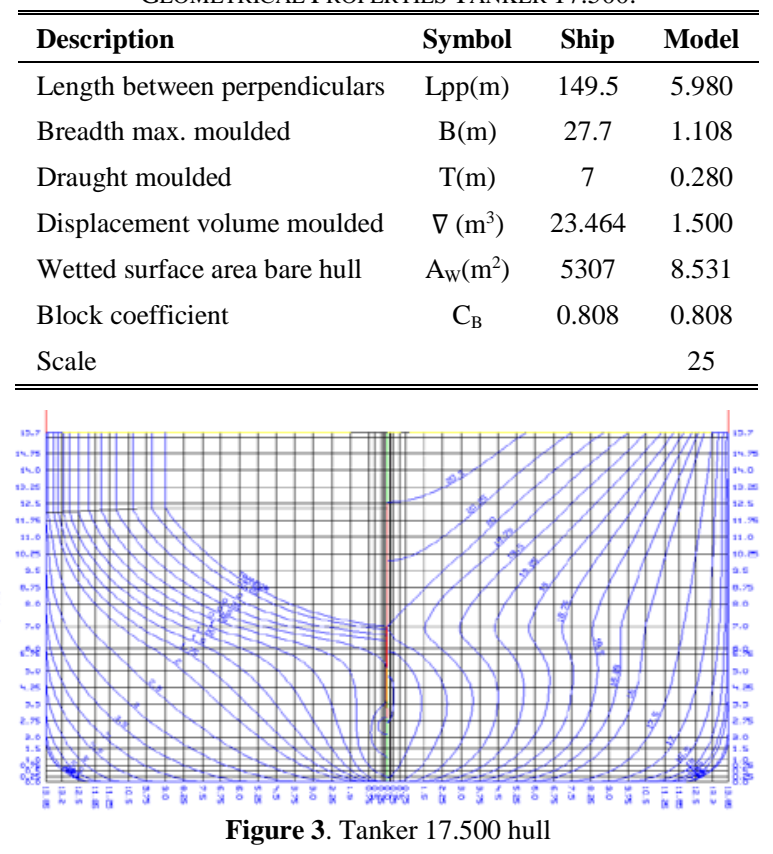

\section{B. Mathematical Modelling}

A mathematical model based on Reynolds Averaged Navier-Stokes equations. A detailed description of the mathematical model and numerical methods for solving are presented in [6]. Equations (1) and (2) are the incompressible RANS equations in tensor form and Equation (3) is the volume fraction transport equation.

$$
\begin{aligned}
& \frac{\partial\left(\rho U_{i}\right)}{\partial t}+\frac{\partial\left(\rho U_{i} U_{j}\right)}{\partial x_{j}}=-\frac{\partial P}{\partial x_{i}}+\frac{\partial}{\partial x_{j}}\left[\mu\left(\frac{\partial U_{i}}{\partial x_{j}}+\frac{\partial U_{j}}{\partial x_{j}}\right)\right]- \\
& \frac{\partial}{\partial x_{j}}\left(\rho \overline{u_{\imath}^{\prime} u_{J}^{\prime}}\right)+f_{i} \\
& \frac{\partial U_{i}}{\partial x_{i}}=0 \\
& \frac{\partial c}{\partial t}+\frac{\partial\left(c U_{j}\right)}{\partial x_{j}}=0
\end{aligned}
$$

where $\rho$ is the fluid density, $\bar{u}_{i}$ is the averaged velocity vector, $\rho \overline{u_{\imath}^{\prime} u_{\jmath}^{\prime}}$ is the Reynolds stress tensor, $\bar{p}$ is the mean pressure and $\mu$ is the dynamic viscosity.

Calculation have been performed with the commercial CFD code ANSYS CFX. The code is based on Finite Volume method The physical parameters and solver settings used to define the numerical solution are provided

\begin{tabular}{|c|c|}
\hline Property & Mesh (full Hull) \\
\hline Type of mesh & unstructured (tetrahedral) \\
\hline No. of elements & 3.618 .920 \\
\hline Domain Physics & $\begin{array}{l}\text { Homogeneous Water/Air multiphase, SST } \\
\text { turbulence model, Automatic wall function, } \\
\text { Buoyancy model -density difference, Standard } \\
\text { free surface model }\end{array}$ \\
\hline \multicolumn{2}{|r|}{ Boundary physics: } \\
\hline Inlet & $\begin{array}{l}\text { Inlet with defined volume fraction, flow speed = } \\
1.029-1.541 \mathrm{~m} / \mathrm{s} \text {, turbulence intensity } 0.05\end{array}$ \\
\hline Outlet & $\begin{array}{l}\text { Opening with entrainment with relative pressure } \\
=\text { hydrostatic pressure }\end{array}$ \\
\hline Bottom & Wall with free slip condition \\
\hline Side wall & Symetry \\
\hline Top & $\begin{array}{l}\text { Opening with entrainment with relative pressure } \\
0 \mathrm{~Pa}\end{array}$ \\
\hline Hull/T17500M & Wall with no slip condition \\
\hline \multicolumn{2}{|r|}{ Solver settings: } \\
\hline Advection scheme & High Resolution (ANSYS 18.1) \\
\hline Timescale control & Physical timescale function: $0.01[\mathrm{~s}]$ \\
\hline Convergence criteria & Residuary type: RMS, Target: 0.0001 \\
\hline Multiphase control & Volume fraction coupling \\
\hline \multicolumn{2}{|r|}{ Processing Parameters: } \\
\hline Computing System & Win Prof. 10 64bit \\
\hline Run type & Parallel (4 core nodes each with 32 GB RAM) \\
\hline
\end{tabular}
in table 2.

TABEL 2.

NUMERICAL SIMULATION PROPERTIES

The computations using free-surface model apply, pressure outlet, and symmetry conditions for the inlet, the outlet, and center/side/top/bottom boundary planes, respectively. The standard wall function is used to enhance computational efficiency. All calculations were conducted for the unappended hull form.

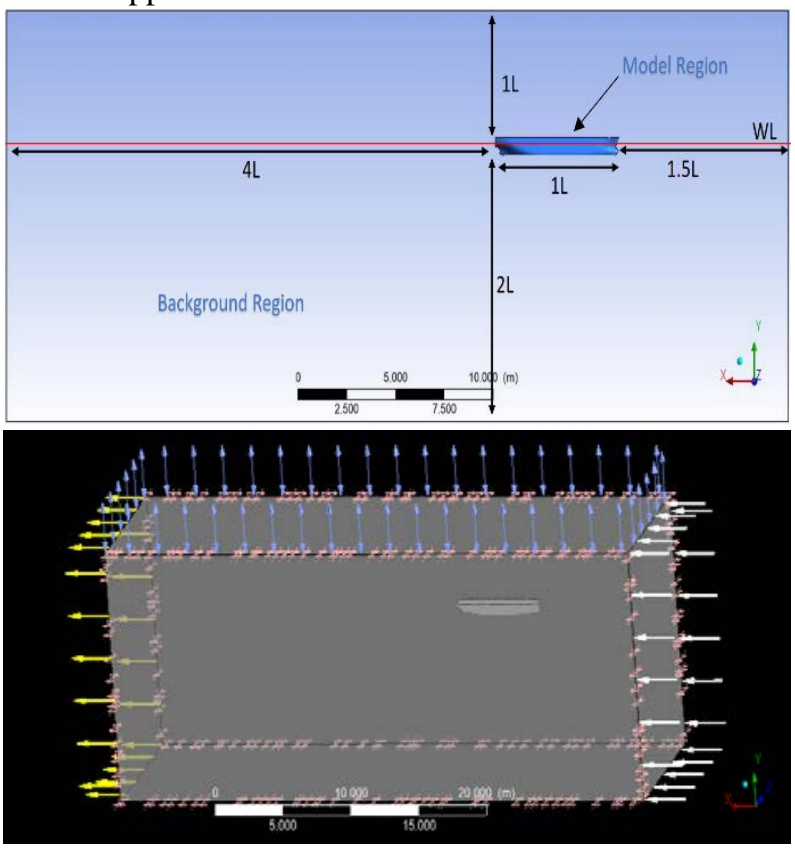

Figure 4. Dimensions of computational domain 
The Shear Stress Transport (SST) turbulence model has been used in the simulations. Two-equation models solve two additional equations for the eddy viscosity, one for the turbulence kinetic energy $(k)$, and one for its dissipation rate (typically $\varepsilon$ or $\omega$ ). These models are by far the most popular and have shown to be able to give accurate predictions in ship hydrodynamics, especially certain versions of the $k-\omega$ model [7][8].

To solve the governing fluid equations in ANSYS CFX, the fluid domain is subdivided into a finite number of cells, cell sizes in the domain are gradually refined towards the regions where high gradients of velocity and pressure are expected. A prismatic layer is generated around the hull model, defining the appropriate cell thicknesses in order to resolve the boundary layer.

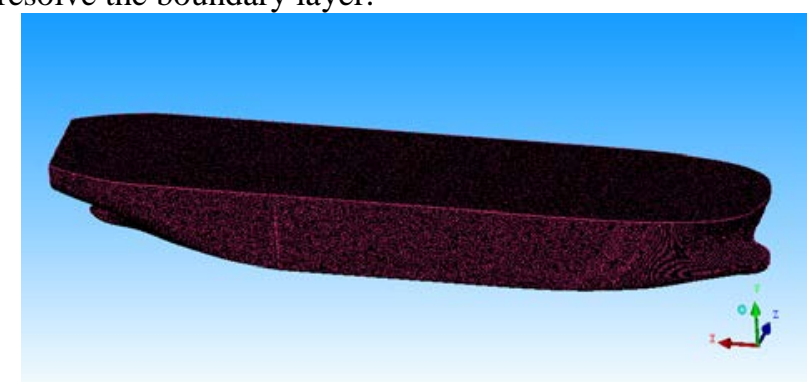

Figure 5. Computational Grid on Tanker 17.500 hull Surface for Ansys CFX

The grid generator of Ansys CFX (ICEM CFD) was used for meshing the computational domain with tetrahedral grid ele- ments of 3,651,386. The mesh was refined over the hull surface and in the region of water free surface near the ship hull in order to predict correctly the value of hull pressure resistance and to get a sharp free surface. Figure 5 show the unstructured tetrahedral grid of the computational domain and on the VLCC hull surface used with Ansys CFX solver.

Convergence was assessed by plotting the flowing parameters against the number of iteration: Residuals for mass, momentum and turbulence (target criteria = 1E-4) and Drag forces (X directions). The maximum number of iterations was equal to 800 . However, if the convergence criteria are reached for all residuals, the simulation was stopped before reaching 800 iterations.

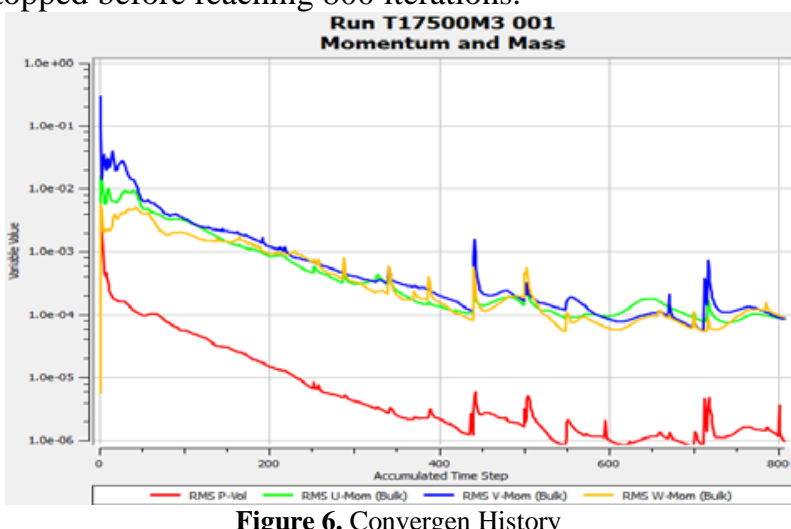

\section{RESULTS AND DISCUSSION}

Results of CFD computed resistance consists of frictional (tangential) and pressure (normal) contributions. The total resistance coefficient presented qualitatively and compared with the experiment data presented in Figures 6 that the agreement between the computed value of the total resistance coefficient and the value provided by the experiments [5]. Comparison of computed results with the measured data is performed for the evaluation of the accuracy of CFD simulations. Seven cases of nondimensional parameters Fr (Froude number) based on the ship length and free stream velocity are selected for comparison with the presented numerical method, and listed in table 2. It can be seen from table 2 .

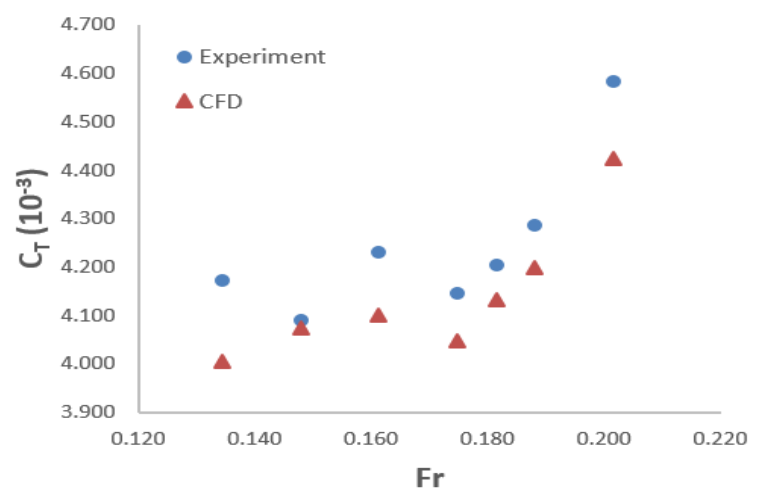

Figure 7. Comparison of The Total Resistance Coefficient for Tanker 17.500

The mean value of the total resistance force is calculated, but taking into account only the values of the last $5 \%$ of physical time. Relative deviations are calculated according [9] the following equation is:

$$
R D[\%]=\frac{R_{T}^{C F D}-R_{T}^{E X P}}{R_{T}^{E X P}} .100
$$

where $R_{T}^{C F D}$ is the total resistance obtained numerically and $R_{T}^{E X P}$ is the total resistance obtained experimentally. The is negative that mean the result obtained with numerical simulation underestimates the measured value.

TABLE 2.

COMPARISON BETWEEN EXPERIMENTALLY AND NUMERICALLY OBTAINED TOTAL RESISTANCE VALUES

\begin{tabular}{cccc}
\hline \hline Fr & Exp (N) & CFD (N) & Error (\%) \\
\hline 0,134 & 18.675 & 17.945 & -3.91 \\
0,148 & 22.159 & 22.096 & -0.28 \\
0,161 & 27.284 & 26.448 & -2.95 \\
0,175 & 31.385 & 30.657 & -2.28 \\
0,181 & 34.298 & 33.744 & -1.63 \\
0,188 & 37.529 & 36.835 & -1.97 \\
0,202 & 46.134 & 44.548 & -3.38 \\
\hline \hline
\end{tabular}

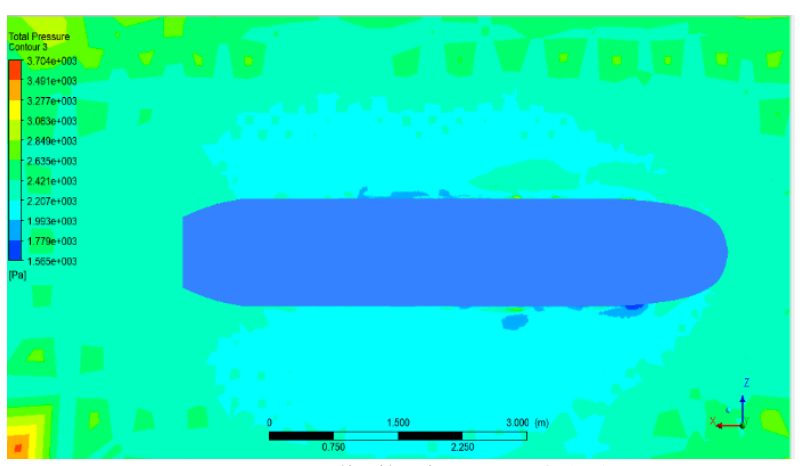

Pressure disribution Fr at 0.161 


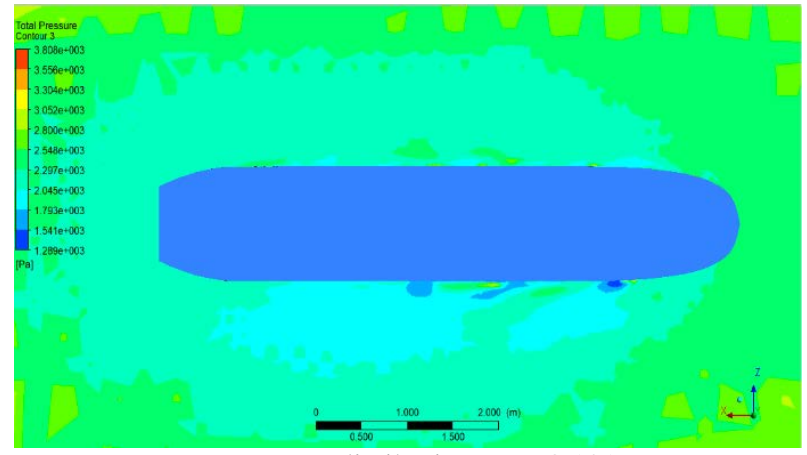

Pressure disribution at Fr 0.181

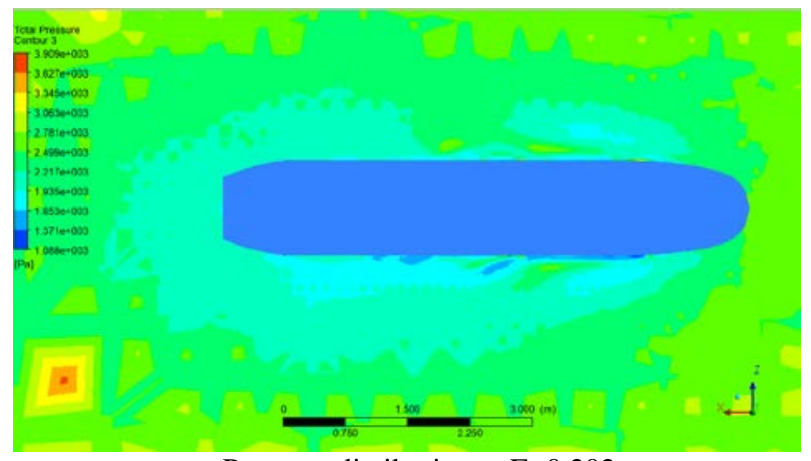

Pressure disribution at Fr 0.202

Figure 8. Pressure distribution of Tanker 17.500 at range of Fr

At Fr 0.161 the pressure ranged from $1.565 \times 10^{3} \mathrm{~Pa} \sim$ $3.704 \times 10^{3} \mathrm{~Pa}$. The total resistance (Rt) resulted from simulaton is $26.448 \mathrm{~N}$, at Fr 0.181 the pressure ranged from $1.289 \times 10^{3} \mathrm{~Pa} \sim 3.808 \times 10^{3} \mathrm{~Pa}$. The total resistance (Rt) resulted from simulaton is $33.744 \mathrm{~N}$ and at Fr 0.202 the pressure ranged from $1.088 \times 10^{3} \mathrm{~Pa} \sim 3.909 \times 10^{3} \mathrm{~Pa}$. The total resistance (Rt) resulted from simulaton is $44.548 \mathrm{~N}$. In the flow around a ship, the colours represent a separation zone occurring behind the ship that creates a complicated turbulent flow field including large eddies. Inaccurate modeling of this zone causes the error to advance in flow direction.

It should be mentioned that no measured flow field is available, therefore in this and following sections, only computed flow field will be presented.

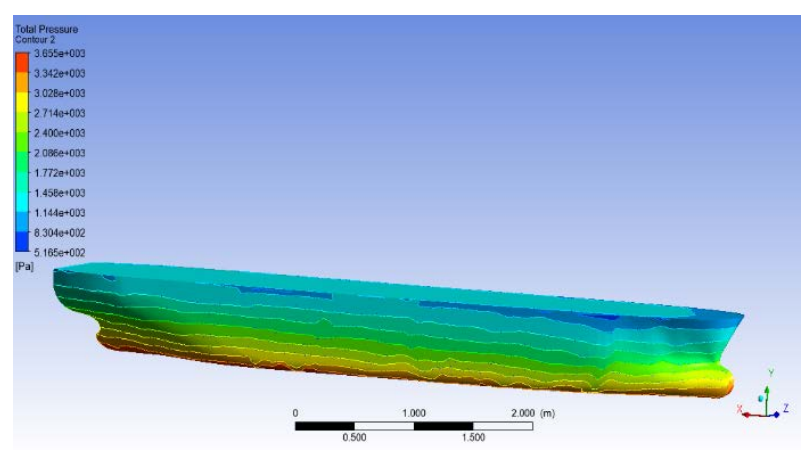

Pressure on hull surface Fr at 0.161

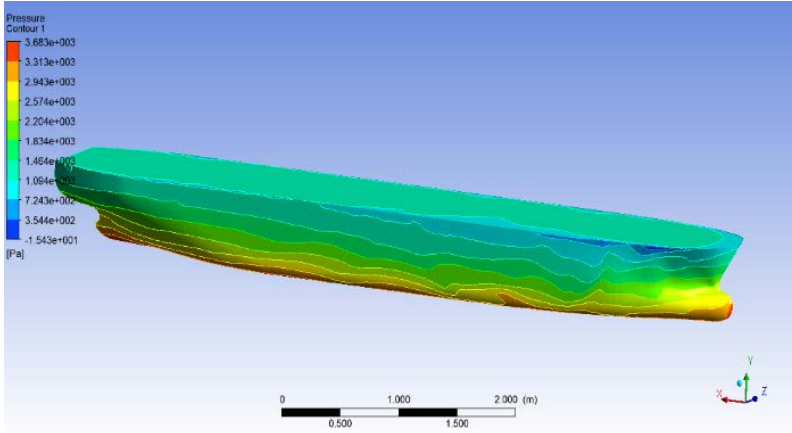

Pressure on hull surface Fr at 0.181

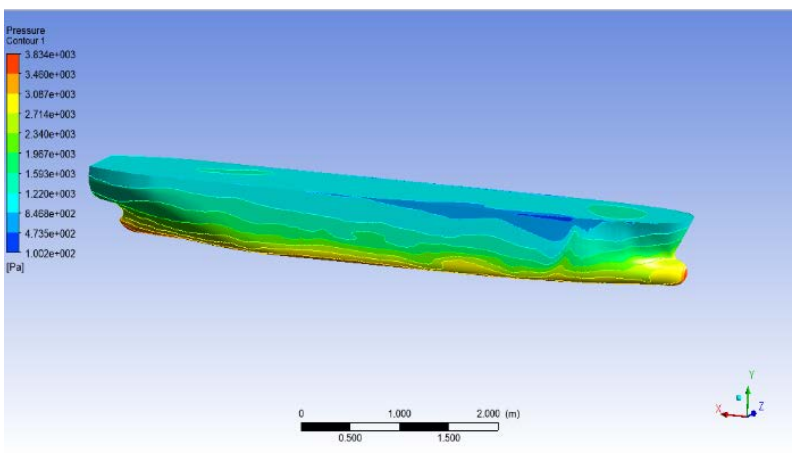

Pressure on hull surface at Fr 0.202

Figure 9. Pressure on the ship hull surface

As shown above figure 9, the predicted pressure distribution offers a global view of the flow around the hull and an explanation of the forces and moments. Solid contour lines represent positive pressure, while dashed contour lines indicate negative values. A clear difference in the pressure distribution between bottom and upper model. In general, a high pressure region is noted at the bow due to stagnation, the explanation is that the high-speed flow from the bow is slowed down.

\section{CONCLUSION}

Principles of RANSE-based (Reynolds Averaged NavierStokes Equations) numerical modelling of a flow around the Tanker 17.500 model hull are introduced with the application of the CFX software package in the field of ship hydrodynamics. The comparisons between the numerical and experimental resistance components show the agreement of the flow code Ansys CFX for the value of $\mathrm{C}_{\mathrm{T}}$. The predicted pressure distributions have offered an insight into the forces and moments acting on the hull. A high pressure region appears at the bow of the hull due to the stagnation

Experiences from these preliminary studies provided knowledge of the numerical error/uncertainty, and most importantly, of the modeling errors in the RANS computations of this kind.

The subjects of future research will be the extension of the presented approach to the analysis of the practical naval problem like seakeeping and maneuverability. 


\section{ACKNOWLEDGEMENT}

The first author, in particular, expressed her gratitude to The Ministry of Research and Technology (Ristekdikti) which funding her $\mathrm{PhD}$ program at ITS undercontract number 07/S3/D/PTB/XI/2015.

\section{REFERENCES}

[1] ITTC, "The Specialist Committee on Computational Fluid Dynamics," in Proceedings of 26th ITTC - Volume II, 2011.

[2] F. Stern et al., "Computational ship hydrodynamics: Nowadays and way forward," in International Shipbuilding Progress, 2013, vol. 60, no. 1-4, pp. 3-105.

[3] J.-S. Kouh, Y.-J. Chen, and S.-W. Chau, "Numerical study on scale effect of form factor," Ocean Eng., vol. 36, no. 5, pp. 403-413, Apr. 2009.
[4] B. J. Guo, G. B. Deng, and S. Steen, "Verification and validation of numerical calculation of ship resistance and flow field of a large tanker," Ships Offshore Struct., vol. 8, no. 1, pp. 3-14, Mar. 2013.

[5] Indonesian HydrodynamicLaboratory, "Technical Report NO. IHLBPPT/C-0077/IV/2012,” 2012

[6] J. H. Ferziger and M. Perić, Computational Ship Hydrodynamics: Nowadays and Way Forward. Berlin, Heidelberg: Springer Berlin Heidelberg, 2012.

[7] F. Menter, "Zonal Two Equation k-w Turbulence Models For Aerodynamic Flows," in 23rd Fluid Dynamics, Plasmadynamics, and Lasers Conference, 1993.

[8] F. R. Menter, M. Kuntz, and R. Langtry, "Ten Years of Industrial Experience with the SST Turbulence Model," Turbul. Heat Mass Transf. 4, 2003.

[9] A. Farkas, N. Degiuli, and I. Martic, "Numerical Simulation of Viscous Flow Around A Tanker Model," Brodogradnja, vol. 68, no. 2, pp. 109-125, Jun. 2017. 